enough to do more good. The cataracts have not increased, and she gains instead of losing strength; but, up to the present, she returns about every three months with glycosuria, but no polyuria.

CASE vi.-Mr. D., aged 59, had frequent rheumatic pain and stiffness of joints, also cramps. I first attended him on January 13th, this year for a peculiar clonic spasmodic action of the left arm, and at the same time discovered that he had been suffering for about six months from diabetes, passing daily twelve pints of saccharine urine, of specific gravity 1042. I prescribed salicylic acid in mixture, 36 grains daily, and ordered him to avoid sugar and potatoes, also to take whiskey instead of beer. In four days, the quantity of urine was reduced to four pints in the day, containing less sugar, and specific gravity 1025. He is still under treatment. He has had no return of the spasms or rheumatic pains; the specific gravity of the urine varies between 1025 and 1032 , but the quantity has no day exceeded four pints.

In addition to these six cases of glycosuria in rheumatic persons, I have tried the salicylic treatment in four other cases in which no rheumatic symptoms existed, and, in all, failed to make any impression on the polyuria or sugar. Two of these cases were carefully observed in hospital ; they improved on restricted diet and sedatives, but not on salicylir: acid. These four were doubtless glycosuria of hepatic origin; in age they were under 30 , while the cases I have described were all over 50 .

General Remarks. - The first and most marked effect of the salicylic treatment in the glycosuria of rheumatic persons, is the almost complote removal of the distressing polyuria which accom. panies it.

In Case vr, after four days' treatment, the daily evacuation of urine was reduced from twelve to four pints, and, in all the cases, this effect was one of the earliest and most constant ; at the same time there was a considerable fall, both in the specifie gravity of the urine and its proportion of sugar; even when the treatment fails to remove the sugar entirely, it reduces it to such a trifling amount, that the patient is unconscious of any ailment, and gains in Hlesh and strength. This improvement persists for weeks after suspending the medicine, as is the case with two patients now under observation; the quantity of urine never exceeds three to four pints in the day, nor does the specific gravity rise above 1028 or 1030 , though containing sugar. Even this condition must be safer and less serious than when the patient is passing daily nine to twelve pints of saccharine urine, of a specific gravity of 1040 and upwards.

As to diet, the careful restriction which is so imperative in the diabetes of hepatic origin is not so necessary in this kind; still I think it greatly helps to restrict the formation of glucose in the system, by prohibiting potatoes, farinaceous puddings, and sugar, as much as possible.

In administering salicylic acid, the following mixture has given good results : B Salicylic acid $3 \mathrm{ii}$, bicarbonate of soda $3 \mathrm{j}$, carbonate of ammonia $\bar{j}$; mix in water $\mathbf{z} i$, and, when effervescence has subsided, add water to $\tilde{3}$ xii. An eighth or twelfth part to be taken three times a day. This is a soluble neutral mixture, and is not unpalatahle when given in a wineglass of water, with a little tincture of orangepeel added. The ammonia prevents any depressing effects. I have tried the free acid made into three-grain pills with mucilage, as recommended by Dr. Latham in rheumatic fever, but have not found them superior to the mixture, while many patients object to swallow. ing five or six pills as a dose.

It is a matter of much importance, with regard to treatment, to be able to distinguish between the two kinds of diabetes. The presence or absence of rheumatic arthritis, pains, and cramps, is often sufficient; but Dr. Latham has recently called attention to a more certain mode of distinguishing between the two, as he has found that in the diabetes of rheumatic persons - that is, originating in the muscular tissue-the urine contains some substance which dissolves cuprous oxide; so that a larger quantity of Fehling's test has to be added before getting the brown precipitate in this urine, than in the diabetic urine of hepatic origin. I have lately been able to confirm this observation.

To judge from the proportion of cases of diabetes in rheumatic persons which I have met with in this neighbourhood, this kind of glycosuria can be by no means rare; and the early treatment of it with a salicylic acid offers a real hope of cure, or, at any rate, it will relieve and prevent that tendency to wasting and exhaustion which has but one issue.

Presentation. - Dr. A. Harrison Thomas, Senior Medical Officer to the Fisherton House Asylum, was, on April 16th, presented "ith an address, together with an inkstand and tankard, by the officials of that institution, on the occasion of his resigning his appointment.

\section{NOTES OF A CASE OF SUPRAPUBIC LITHOTOMY.}

\section{By J. RUTHERFORD MORISON, M.D., F.R.C.S.Edin., Hartlepool.}

Removal of Three Purc Uric Acid Stones ; largest, about the sine of " Cocoa-nut, weighing one pound six and three-quarter ounces, long circumference 12 inches, short circumference 93 inches.

S., agod 52, married, a seafaring man, resiling at West Hartlepor], complained of pain and difficulty with his urine. His general health had been good, with the exception of the trouble complained of. $\mathrm{He}$ had been somewhat addicted to alcoholic excess. He looked a strong man, but much worn by pain and loss of rest.

For the last thirty years, he had had attacks of pain and difficulty in micturition. He thought that an accident, a fall on the perinæum over a railing, which he met with when a boy, might have been the cause. During the attacks, he had had a frequent desire to micturate, accompanied by straining pains in the perinæum and rectum, and a shooting into the point of the penis. These attacks lasted a variable time, occasionally passing off in a few days, at other times requiring months. He said they had to reach a height, after which followed a gradual return to health, and for a time he remained perfectly well. Several years ago, during one of the attacks, he passed blood with his urine. At different times he had consulted a variety of physicians and surgeons, but nothing did him any good except morphine, which relieved his pain. He had been frequently sounded for stone, but withont result.

His present attack began four months ago in the usual way, with painful and frequent micturition, for which, up to the time of my seeing him, he had been under medical care, and steadily becoming worse. At the time of my first seeing him, I was going a way for three weeks ; therefore, on examining his urine, and finding it to contain one-third albumen, some pus, and to be of a low specific gravity (1008), I ordered him to live on milk, and to take 15 minims of tincture of perchloride of iron three times a day, postponing any instrumental interference till my return.

On August 14th, three weeks having expired, I again visited him. So far as could be ascertained, all his organs were healthy, with the exception of the genito-urinary system. He was wearing an urinal, as his urine was constantly dribbling away. As a conscquence, his thighs were excoriated, and he had a strong urinous oiour. On palpation, a rounded swelling could be felt in his lower abdomen, $r$ ach ing midway between the umbilicus and pubes, which was dull on percussion, and pressure on which caused a desice to micturate, nnil the escape of some urine by the natural channel. P'ressure ovor both kidneys, posteriorly, caused pain. By the ser.tim, a round, hasd, tender swelling was easily felt, projecting into the lower part. A solt rubber catheter entered as far, apparently, as the prostatic uritha, but here it hitched, causing great pain, and about a teaspoonful of urine $t$ scaped in little gushes. The catheter conld not tnter the bladder. I arranged, after explaining that, in his dangerous state, even the passing of an instrument and the emptying of his hladder was attended by considerable risk, to give him ebloroform the fol. lowing day, and make a thorough exploration.

August 15th. On giving chloroform, the distended bladder could be distinctly felt as a rounded swelling in the luwer abdomen. A soir coudé instrument struck at the same spot as the one introduced jesterday, and no more urine could be obtained through it. $A$ silver catheter, now tried, struck a stone at the point of obstruction lying in the urethra, and conld not be passed beyond it. I arranged to make an incision, and, by that means, empty his bladder next day.

August 16th. The staff, when introduced, hitched on the urethral calculus, but passed on into the bladder, where it struck another calculus. The ordinary (as for lateral lithotomy) incision was now made, and bled profusely from the whole surface. The transverse perineal artery was so active as to be formidable, and a Péan's forceps was fixed on each end. When the urethra had been incised, a small flat stone escaped into the wound, and was extracted with my finger, which was then passed into the bladder on to the stoue ihert, and the staff was removed. The stone was of such larce size, that I enlarged the wound in the bladder with a probe-pointed listoury before introducing the largest size of lithotomy-forceps. Expanding the forceps widely, I grasped the stone, which wis so large and of such a shape that the instrument slipped off. After repeating the process in a variety of directions, it was plain that the stone could not be removed through this incision, and that, if the stone were to be had, it must be by the suprapubic operation. The wound had all 
along bled profusely from its whole surface, and by this time the patient had lost at least a pint of blood. A sponge was packed into the perineal wound, the suprapubic incision made, and the bladder opened above the pubes on the stone; a matter of little difficulty, as the stone was pushing forwards the anterior bladder-wall. The incision in the skin was extended upwards for about four inches from the pubic bone, the bladder-wall being opened for about two inches up to the reflection of the peritoneum. The lithotomy-forceps was again introduced, but had no power, and slipped. There was the same difficulty as before. The midwifery-forceps of a neighbouring practitioner was now sent for, and, on its arrival, one blade was introduced at a time, as in an ordinary instrumental delivery. The entrance of the first blade was followed by a gush of putrid urine, which escaped over the abdominal wound, and must inevitably have run into the peritoneal cavity had it been opened.: This urine, about two ounces, was lying in the base of the bladder under the stone, and at a lower level than the urethral opening. The forceps being locked, the stone was easily removed by slow and gentle traction, the wound in the bladder expanding without laceration, and no further obstruction being encountered because of the Iong incision through the superficial soft parts. The bladder-wall was very much thickened, and so vascular that it bled freely. Lying at the lowest part of the bladder was another small flat stone, which was now removed.

The operation was completed by the introduction of two deep and three superficial sutures of catgut into the abdominal wound, leaving only the lower half open; by stitching a full sized drainage-tube reaching the bladder into the perineal wound; by flushing out the bladder and wounds with boracic lotion; and, finally, by the introduction of a large sponge, with Péan's forceps attached, into the blad. der to stop the oozing from its interior still going on. The operation occupied three quarters of an hour, including the delay occasioned by having to send for forceps.

An hour afterwards, the sponge in the bladder was removed by means of the Péan's forceps, which was left attached, and all the bleeding had ceased. The patient had a fair pulse, but had not yet rallied from the cold, chloroform, and shock.

August 16 th, evening. Fair pulse, 110 ; temperature $97^{\circ}$. He had not yet recovered from the shock, and was inclined to be cold. A hypodermic injection of one-sixth of a grain of morphine was made, and some hot inilk and water given.

August $17 \mathrm{th}$, morning. Temperature $97^{\circ}$. The hands were still cool, but the body warm and perspiring. He had had a good night; he had slept three or four hours, and had taken milk freely without sickness. 1 P.M., temperature 97.6 , pulse $112 ; 3.40$ P.M., temperature $99^{\circ}$, pulse 120 ; 10 P.M., temperature $102.6^{\circ}$, pulse 160 . T'en grains of yuirine, and ten grains of compomd ipecacuanha powder, were ordered.

August 18th, 1 A.M. Temperature $100.2^{\circ}$, pulse $140 ; 8.20$ A.M., temperature $97.4^{\circ} ; 3.20$ 1.M., temperature $98.8^{\circ} ; 8$ P.M., temperature $99^{\circ}$, pulse 117. After this, his temperature only once reached $100^{\circ}$. For several nights he required morphine to make him sleep, not because of pain, but of restlessness.

August 19th. Most of the urine escaped by the abdominal incision, in spite of the fact that the perineal tube was large and patent. The tube was removed in consequence. The secretion of urine was very free, and had been ever since the operation. To-day he took a quantity of egg-flip; he looked much better, but his tongue was dry, and he was disposed to hiccough. One grain of calomel was ordered to be taken every four hours.

August 21st. His pulse occasionally intermitted, and had kept up to about 120 since the operation. He was ordered 10 minims of tincture of digitalis every four hours. The tongue was much cleaner. He asked for and relished some tea and toast.

August 22nd. Most of the urine escaped through the abdominal wound; and a tendency, apparently, for it to find its way into the urethra had caused some pain. I passed a full sized drainage:tube through from the perineal to the abdominal opening, and ordered the bladder and tube to be syringed out from above every four hours with warm boracic lotion. The patient seemed very well and strong; pulse 100, temprature normal. He could not, however, sleep well at nights ; the urı

August 27 th. He was very well and strong. The upper part of the abdominal wound was healed; the lower part was granulating, and both it and the perineal wound had closed in so as to embrace the drainage-tubes. His diet had been gradually improving; to-day he was allowed to have for dinner chicken with vegetables, pudding, and a glass of beer. After dinner he enjoyed a smoke, and was anxious to know if he soon could get up a little. He was in excellent spirits about himself.
August 28th, morning. He looked rather depressed, and said he did not feel in such good spirits. He had had hiccough occasionally; but, as his pulse was good, and temperature normal, the wounds looked well, and the secretion of urine was free, no importance was attached to it, as, even when fairly well for some months, he had sometimes had it. In the evening the hiccough was much worse; it never let him rest. The tongue was dry ; pulse 120 , temperature $98.4^{\circ}$. He was very thirsty, drowsy-looking, and low-spirited. He said he was going to die. Hypodermic injection of morphine, and a variety of other things, were tried.

August 29th. The hiccough never ceased. He had been delirious all night, wanting to get out of bed, etc. He died early in the morning. No post mortem examination could be obtained, though there could be little doubt from the history and his condition that the ureters were dilated, and the kidneys diseased.

\section{ENDOMETRITIS.}

Read before the Glasgow Obstetrical and Gynoccological Socicty. BY ROBERT BELL, M.D.; F.F.P.S.G., ETC.,

Physician to the Glasgow Institution for Diseases of Women.

Two reasons have influenced me in my selection of endometritis as the subject of this paper: 1, because this morbid condition is so frequently met with; and 2 , because its existence is so frequently overlooked by the general practitioner. I do not, of course, wish it to be inferred, when I speak of endometritis, that I believe that the endometrium, in any great number of cases, is affected alone-that is, without the parenchyma of the uterus being likewise involved; but, as it is principally through the lining membrane of the organ that we are able to reach its more remote structure when treatment is being employed, and as the indications of restored health are reflected through the canal, the health of this membrane must always be viewed as indicative of the health of the uterus as a whole. I have just observed that this diseased condition of the uterine canal is often overlooked; but I go farther, and would point out that not only is it passed by unrecognised, but one of the manifestations of the disorder, and one which of itself is of little account, is accepted as the disease, and, even when this is detected, it is misnamed. I refer to the so-called ulceration of the womb, which, so far from being an ulcer, on the contrary, is a hypertrophic condition of the cervix. This partakes no more of the nature of an ulcer than an ectropion of the eyelid does. Papillary and follicular ulceration of the cervix are terms in our nomenclature which never should have existed. Certainly the strawberry appearance of the cervix, which frequently, but by no means constantly, is a part of endometritis, is a most prominent symptom ; and to observe its gradual disappearance is a most welcome sight; but to treat it per se by local applications, in the expectation that the patient will thus have her health restored, will surely end in disappointment. What we have been long in the habit of call. ing an ulcer of the womb, in common parlance, is, we now know, an ectropion of the cervical membrane due to hyperplasia, which results in the mucous membrane being crowded outwards; and this hyperplasia is due to endocervicitis. Let us now, however, consider endometritis, not in part, but as a whole; and it will be my endeavour not only to demonstrate what I consider the safest and surest means of arriving at a correct diagnosis, but also to detail my experience in its treatment.

First, then, its etiology must have careful attention, as this is very varied. The causes of endometritis are frequently at the onset appa. rently very trivial, so much so, that it is not a matter of surprise that they are often overlooked; and yet these may advance so insidiously, that quite unexpectedly they come to be mighty factors in the produc. tion of this most painful and trying disorder. We cannot be surprised, however, that a woman should suffer intensely and long before applying for relief, when the uterus is the seat of disease. It must always be a great effort on her part to submit to examination, and to a course of treatment. Symptoms are thus apt to be pretty well advanced, and, therefore, more difficult to remove than otherwise they would be, before they come under observation. As each menstrual period is accompanied by a physiological hyperæmia of the uterus, which in the healthy woman passes off with the emptying of the surcharged vessels, it will not be difficult to comprehend how, if any inflammatory condition be present as well, though it may not b3 sufficiently marked to indicate itself by any decided symptoms during the intermenstrual repose, this will be so aggravated at the period of 